\title{
PLS path modeling - a confirmatory approach to study tourism technology and tourist behavior
}

Tobias Müller and Florian Schuberth

Department of Design, Production and Management, Universiteit Twente, Enschede, The Netherlands, and Jörg Henseler

Department of Design, Production and Management, Universiteit Twente, Enschede, The Netherlands and Nova Information Management School, Universidade Nova de Lisboa, Lisbon, Portugal
Received 30 September 2017 Revised 6 January 2018 1 March 2018 Accepted 7 March 2018

\begin{abstract}
Purpose - As technology in tourism and hospitality (TTH) develops technical artifacts according to visitors' demands, it must deal with both behavioral and design constructs in the context of structural equation modeling (SEM). While behavioral constructs are typically modeled as common factors, the study at hand introduces the composite into TTH to model artifacts. To deal with both kinds of constructs, this paper aims to exploit partial least squares path modeling (PLS-PM) as a confirmatory approach to estimate models containing common factors and composites.
\end{abstract}

Design/methodology/approach - The study at hand presents PLS-PM in its current form, i.e. as a fullfledged approach for confirmatory purposes. By introducing the composite to model artifacts, TTH scholars can use PLS-PM to answer research questions of the type "Is artifact xyz useful?", contributing to a further understanding of TTH. To demonstrate the composite model, an empirical example is used.

Findings - PLS-PM is a promising approach when the model contains both common factors and composites. By applying the test for overall model fit, empirical evidence can be obtained for latent variables and artifacts. In doing so, researchers can statistically test whether a developed artifact is useful.

Originality/value - To the best of the authors' knowledge, this is the first study to discuss the practical application of composite and common factor models in TTH research. Besides introducing the composite to model artifacts, the study at hand also guides scholars in the assessment of PLS-PM results.

Keywords Guidelines, Artifact, Construct modeling, Partial least squares path modelling Test for overall model fit

Paper type Technical paper

\section{摘要}

䂰究目的 - 因为旅游酒店科技 (TTH) 根据游客需求而定制科技产品, TTH必须在结构方程模型 SEM) 下结合游客行为和设计等变量。一般行为变量在模型中是常见因子, 本硎究将这些变量编入 TTH结构成为模块。本研究采用PLS-PM方法来预估含有隐性变量和模块的模型。

(C) Tobias Müller, Florian Schuberth and Jörg Henseler. Published by Emerald Publishing Limited. This article is published under the Creative Commons Attribution (CC BY 4.0) licence. Anyone may reproduce, distribute, translate and create derivative works of this article (for both commercial \& non-commercial purposes), subject to full attribution to the original publication and authors. The full terms of this licence may be seen at http://creativecommons.org/licences/by/4.0/legalcode
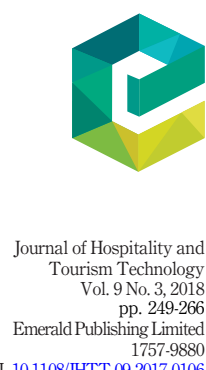
DOI 10.1108/JHTT-09-2017-0106 


\section{JHTT 9,3}

㸴究设计/方法/途径 - 本硎究设计PLS-PM模式, 即确定性全变量方法。TTH学者们通过引进结构形 成模型模块, 使用PLS-PM研究方法, 以回答研究问题“模块xyz有用吗区, 因此对TTH进一步理解。为了 展示复合模型, 本论文采用实际验证。

硏究结果 - PLS-PM在面对模块内存在常见因子和复合模块的结构时是有力方法。实际验证结果通 过整体最佳模型参数, 得到隐性变量和模块。为此, 研究者们能够在统计方法上测量是否开发的模型 模块是否有用。.

㸴究原创性/㸴究价值 - 据作者所知, 本论文是首个㸴究在TTH领域上应用模块和常见因子模型。本 研究引进显性变量在模型模块中, 以指导学者评估PLS-PM结果报告。

\section{Introduction}

New technologies such as the internet and information systems play a pivotal role in tourism and hospitality (Balouchi et al., 2017; Ip et al., 2011; Kamboj and Rahman, 2017). Accordingly, the provision of a company's sound and sustainable information technology (IT) infrastructure has been characterized as a key success factor, a contributor to strategic management (Bilgihan et al., 2011), and a significant driver (Collins et al., 2013; Wang et al., 2015) for the tourism and hospitality industry. When booking online, users tend to consume impulsively as an experience (Holt, 1995; Rezaei et al., 2016) that can be supported, for example, by online word-of-mouth (Blackshaw and Nazzaro, 2006; Gretzel et al., 2008; Pan et al., 2007; Pan and Crotts, 2012) or peer-reviewing (O'Connor, 2008) in terms of, e.g. hotel ratings, ease of use (Di Pietro et al., 2012), hotel website functionality, and security and privacy (Ali, 2016). In general, technology in tourism and hospitality (TTH) considers the interplay of technologies and customers to improve customers' experience in order to increase their purchasing intention. Consequently, it is important to consider consumers' behavior when developing and establishing technology-based offers for travel and tourism.

To address this demand, TTH must combine both design and behavioral research because it develops artifacts according to visitors' needs, such as providing them with green services or using environmental technologies and facilities (Hsiao et al., 2018), aiming to create long-term relationships with customers to achieve a competitive advantage (Huang et al., 2009; Moliner et al., 2007). In doing so, TTH investigates tourists' behavior to design and implement proper IT infrastructure. Thus, it links TTH directly to behavioral sciences. However, because TTH also creates and improves tourism technologies, it can be understood as a design research, i.e. it is a "science of the artificial" (Simon, 1969).

To address both the behavioral and the design research paradigm in empirical research on TTH, structural equation modeling (SEM) is eminently suitable because it allows for expressing theoretical constructs through sets of observable indicators and to relate them via a structural model (Bollen, 1989). In doing so, theoretical constructs from the behavioral sciences are often understood as latent variables, such as customer attributes and attitudes that are typically modeled by a common factor. While this way of construct modeling is widely acknowledged for ontological entities, it does not seem reasonable for design constructs, so-called artifacts, since they are constructed and not measured. To account for this characteristic, the composite model, which assumes a definitorial relationship between the indicators and the construct, can be used (Henseler, 2017).

Generally, two types of estimators can be distinguished in SEM:

(1) covariance-based (CB); and

(2) variance-based (VB) estimators.

While CB estimators, such as the maximum likelihood estimator (Jöreskog, 1969), minimize a discrepancy function of the empirical and the model-implied indicator covariance matrix to obtain the parameter estimates, VB estimators, such as generalized structured component analysis (Hwang and Takane, 2004), build linear combinations of observed variables that 
are subsequently used to estimate the model parameters. Among VB estimators, partial least squares path modeling (PLS-PM) (Lohmöller, 2013) has shown to have favorable properties (Hair et al., 2017a) and is applied in various fields of research, such as marketing (Hair et al., 2012), information systems (Hair et al., 2017b), and human resource management (Ringle et al., 2018). PLS-PM is based on an iterative algorithm to obtain weights used for building linear combinations of observed indicators as proxies for all constructs in the model. Thus, PLS-PM is inherently suitable to deal with constructs modeled as composites. Moreover, in its current form - known as consistent partial least squares (PLSc) - it is able to consistently estimate structural models containing both composites and common factors (Dijkstra and Henseler, 2015a).

The study at hand exploits PLS-PM as a confirmatory tool to bridge behavioral and design research to deal with both research paradigms in TTH, i.e. latent variables from behavioral sciences and artifacts from design research. Besides giving a brief review of PLS-PM in its current form, this study shows how latent variables and artifacts can be operationalized in SEM by applying PLS-PM. While Henseler (2017) introduced the composite as a construct modeling approach for artifacts in advertising research, the study at hand adopts his proposal to model artifacts in TTH. This allows for addressing new research questions of the type "Is artifact xyz useful?", which contributes to a further understanding of TTH. Because the use of PLS-PM as a confirmatory tool is still rare in field of THH (Ali et al., 2018), this study also provides guidance for the assessment of the estimated model.

The remainder of the article is structured as follows: Section 2 briefly reviews the PLS-PM. The specification of the model underlying PLS-PM, i.e. the structural model including the operationalization of the constructs by means of common factors and composites is presented in Section 3. Section 4 discusses model identification which is still a largely neglected topic in the PLS-PM domain but must be ensured prior to the estimation of the model. Section 5 provides guidelines on assessing the common factor and the composite model. Section 6 adopts an empirical example from Rezaei et al. (2016) that demonstrates the two ways of construct modeling. Finally, the paper presents a conclusion and discussion in Section 7.

\section{Partial least squares path modeling}

PLS-PM belongs to the group of variance-based estimators for SEM and was developed by Wold (1975) for the analysis of high-dimensional data in a low-structure environment. In recent years, PLS-PM has been subject to intense scientific debate about its pros and cons. While PLS-PM proponents even call the approach a "silver bullet" (Hair et al., 2011), its opponents call for abandoning its use (Antonakis et al., 2010; Rönkkö et al., 2016). As an outcome of this debate, PLS-PM has undergone various extensions and modifications. In its most modern form, known as consistent partial least squares (PLSc), it is able to consistently estimate recursive and non-recursive structural models containing constructs modeled as composites and common factors (Dijkstra and Schermelleh-Engel, 2014; Dijkstra and Henseler, 2015b). Moreover, it can deal with ordinal categorical indicators (Schuberth and Cantaluppi, 2017; Schuberth et al., 2018), and correlated measurement errors (Rademaker et al., forthcoming). Moreover, a test for overall model fit was introduced, making PLS-PM a full-fledged method for confirmatory purposes (Dijkstra and Henseler, 2015a).

The PLS-PM algorithm creates linear combinations of indicators as proxies for all kinds of constructs, i.e. for latent variables and artifacts. In doing so, it can emulate several of Kettenring's (1971) techniques for generalized canonical correlation analysis (Tenenhaus et al., 2005). Subsequently, these proxies are used to estimate the parameters of the model. In 
JHTT

9,3 the case of the model containing constructs modeled as common factors, the proxies' correlations must be corrected for attenuation to obtain consistent parameter estimates. This approach is known as PLSc (Dijkstra and Henseler, 2015b). Depending on the structural model, i.e. recursive or non-recursive, ordinary least squares (OLS) or two-stage least squares (2SLS) is applied to consistently estimate the model parameters. Moreover, a test for overall model fit was introduced (Dijkstra and Henseler, 2015a), making PLS-PM a fullfledged method for confirmatory purposes.

\section{Model specification}

As the study at hand employs PLS-PM for confirmatory purposes, the researcher must transfer his theory into a statistical model. In the context of SEM, this step means that the nomological net including the conceptual variables must be transferred to a structural model relating the constructs - the representations of the conceptual variables (Sarstedt et al., 2016b). Subsequently, it must be decided how the observed indicators are related to the constructs, i.e. how the constructs are modeled.

\subsection{The structural model}

In confirmatory research, the structural model is theory-based and the prime focus of the research question. It defines which constructs are included in the model and how they are interrelated. Usually, the relationships between the constructs are assumed to be linear and recursive, i.e. the model does not contain any feedback loops.

In specifying their structural model, practitioners must pay particularly attention to omitted but relevant constructs. Such constructs have not been considered in the structural model, even though they explain the dependent construct and are correlated with at least one other construct predicting this dependent construct. Ignoring those omitted constructs leads to inconsistent and biased parameter estimates because of omitted variable bias and therefore to questionable conclusions (Antonakis et al., 2010). One way to deal with this endogeneity issue is the use of the 2SLS estimator for the structural model (Benitez et al., 2016; Hult et al., 2018).

Once the structural model is specified, the researcher must operationalize the constructs from the structural model. For this purpose, the following two sections outline the fundamentally different ways of construct modeling, provide guidelines on construct modeling and present an example from the TTH literature.

\subsection{Construct modeling}

Constructs represent conceptual variables and are the focal entities of SEM. To investigate and relate constructs in a structural model, the researcher must decide how to model these constructs. This decision should be grounded primarily on theoretical reasoning rather than on statistical testing (Borsboom et al., 2003). In recent decades, two ways of construct modeling have been established:

(1) the common factor model to model latent variables, which is well-known in behavioral and social sciences (Jöreskog, 1969); and

(2) the composite model to model artifacts (Henseler, 2017). The existing literature also mentions a third way to operationalize constructs: the causal-formative measurement model (Bollen and Bauldry, 2011).

However, models containing causal-formative measurement models are difficult to be identified (Rönkkö et al., 2016), and therefore, they are not part of this study. Figure 1 


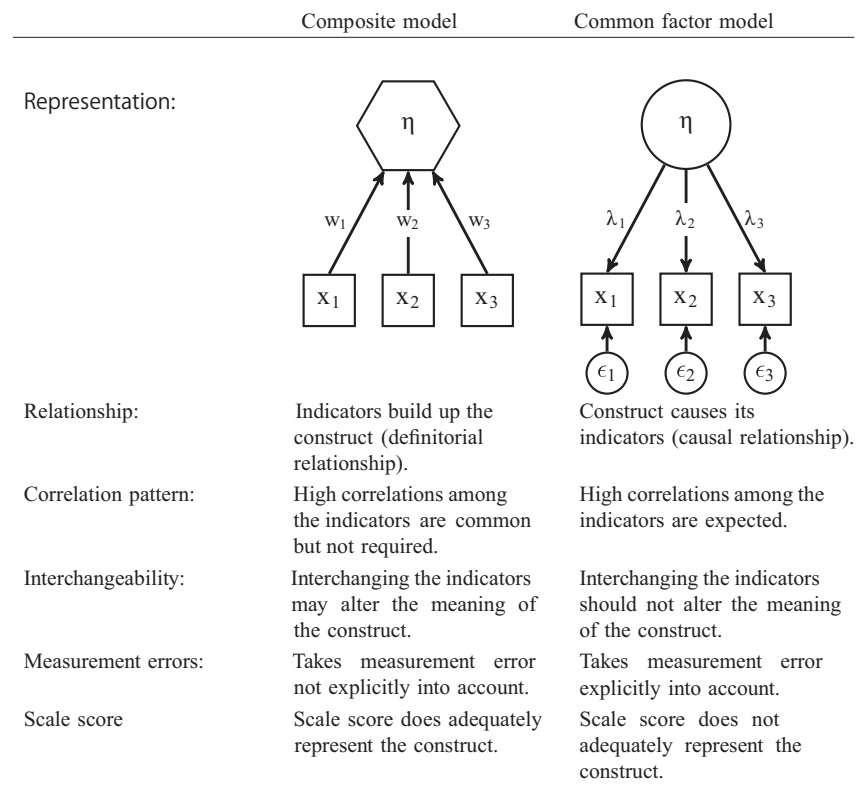

PLS path

modeling

253

Figure 1.

Characteristics of the different modeling approaches

provides the key differences between the two construct modeling approaches which are elaborated in more detail in the following section.

3.2.1 The common factor model. In social and behavioral sciences, a construct is often understood as an ontological entity, such as an ability or an attitude. It rests on the assumption that the construct of interest is not observable but exists in nature, regardless of whether it is the subject of scientific examination (Bollen, 1989). The dominant approach to model constructs in behavioral sciences is the common factor model.

The reflective measurement model, which embodies the common factor, is rooted in the true score theory (Spearman, 1904), which assumes that each observed indicator - the socalled effect indicator - is the consequence of an underlying construct. Thus, the construct causes the structure of inter-correlations among its connected indicators. Therefore, at least in theory, the indicators can be interchanged or dropped without changing the meaning of the construct.

The literature distinguishes between two kinds of reflective measurement models: the multiple-indicator measurement and the single-indicator measurement (Diamantopoulos et al., 2012; Hayduk and Littvay, 2012; Sarstedt et al., 2016a). While the former means that more than one indicator is connected to the common factor, the latter indicates that only one indicator measures the construct of interest. The single-indicator measurement does not explicitly allow for measurement errors to be taken into account, i.e. in the case of measurement error, indicator reliability needs to be adjusted manually based on prior knowledge. However, approaches have been developed to estimate the indicator reliability externally (Wanous and Reichers, 1996).

Typical latent variables in tourism and hospitality that are modeled as common factors include perceived usefulness (Sox et al., 2016), perceived value (Deng et al., 2013), consumers' behavioral intention (Balouchi et al., 2017) and perceived winning in table gaming (Jeon et al., 2013). 
JHTT

9,3
The formal representation of the reflective measurement model is given in the following equation:

$$
\boldsymbol{x}=\lambda \eta+\epsilon,
$$

where the vector $\boldsymbol{x}$ contains the effect indicators, which are the manifestations of the underlying latent variable $(\eta)$, while the factor loadings and the measurement errors are captured in the vectors $\lambda$ and $\epsilon$. In doing so, the measurement error accounts for the remaining indicator's variance, which cannot be explained by the latent variable. Consequently, it comprises all unmodeled causes. Usually, the measurement errors are assumed to be uncorrelated among each other and independent of the underlying common factor. As the construct scores are undetermined in the common factor model, they cannot adequately represent the construct (Steiger, 1979).

Generally, VB estimators cannot consistently estimate models containing common factors, as their estimates suffer from attenuation bias. However, PLSc produces consistent parameter estimates for models containing common factors by using weights obtained by mode $A$ (correlation weights) and applying a correction for attenuation on the parameter estimates. Therefore, the use of PLSc is imperative when the model contains common factors.

3.2.2 The composite model. In contrast to the social and behavioral sciences, in design research constructs represent human-made objects - so-called artifacts. Artifacts have their origin in constructivist epistemology and are built instead of measured. Hence, assuming that an observed indicator is a manifestation of an underlying construct is not reasonable for design constructs.

Accounting for these characteristics, the composite was introduced only recently to model artifacts (Henseler, 2017). The composite model assumes a definitorial relationship between the indicators and the construct, i.e. the indicators make up - but do not cause - the construct. Therefore, following Aristotle, the relation between the indicators and the construct in the composite model is best understood as the material cause rather than the efficient cause.

The following equation displays the formal representation of the composite model:

$$
\eta=x^{\prime} w
$$

where the artifact $(\eta)$ is the result of its weighted indicators, i.e. $\boldsymbol{x}^{\prime} \boldsymbol{w}$, therefore, the construct scores adequately represent the underlying construct.

In contrast to the common factor model, the composite model does not put any restrictions on the correlations among the indicators belonging to one artifact (Henseler et al., 2014a). Consequently, the indicators forming the construct do not necessarily show a particular correlation pattern. However, as the ingredients determine the artifact, interchanging or dropping an indicator likely alters the meaning of the construct. In general, the composite model assumes that the indicators are free from measurement error.

In PLS-PM, the weights to form composites are usually estimated by mode $B$ (regression weights), but in case of high multicollinearity among the indicators, it may be recommendable to use weights obtained by mode $A$ (correlation weights). In general, predefined weights or weights obtained by other routines are also conceivable (Dijkstra, 2013).

As the composite model for confirmatory purposes was introduced only recently, empirical examples cannot be found at first glance in the literature on TTH. However, 
potential artifacts in this field could be computer-based multimedia training (Clemenz et al., 2000), formative referents (King et al., 2017) and various types of e-marketplaces.

\section{Model identification}

An important but often neglected topic in PLS-PM is model identification. Prior to the estimation of the model, identification of the specified model must be ensured, i.e. the parameters can be uniquely retrieved from the indicator covariance matrix. In doing so, model identification distinguishes between three states:

(1) under-identified;

(2) just-identified; and

(3) over-identified.

An under-identified or not-identified model offers several sets of parameters that are consistent with the model constraints, and thus, no unique set of model parameters exists. Consequently, only questionable conclusions can be drawn from the estimated model. In contrast, a just-identified model provides a unique solution for the model parameters; however, in empirical analysis, the overall model fit of such a model cannot be assessed because it perfectly fits the collected data. Hence, in empirical research, an over-identified model is most favorable. Similar to a just-identified model, an over-identified model also has a unique solution; however, it provides more non-redundant elements of the indicator covariance matrix than model parameters. This fact can be exploited to assess the overall model fit, as these constraints should hold for a sample within the limits of sampling error if the model is valid (Section 5).

As PLS-PM always estimates a composite model regardless of whether the constructs are modeled as common factors or composites, the identification rules for composite models must be applied. A necessary condition for ensuring identification is to normalize each weight vector, which is typically done in PLS-PM by scaling the weight vectors, leading to a unit variance for all composites[1]. Besides the normalization, each composite must be connected to at least one composite. Along with the scaling of the weight vectors, all model parameters, i.e. weights and composite correlations, can be uniquely retrieved from the indicator covariance matrix. Apart from connecting the composites via the structural model, it must be additionally ensured that the structural model is also identified. For recursive models with uncorrelated structural error terms, this step is straightforward, as they are always identified (Bollen, 1989, p. 104). However, for more complex composite models, further identification rules are required (Dijkstra, 2017).

Furthermore, only the magnitude of factor loadings and weights for a block of indicators is determined, but not their sign. Hence, in empirical research, it could be that all indicators of a construct have a sign opposite to what one would expect. To address this issue, it is recommended to apply the dominant indicator approach (Henseler et al., 2016), i.e. determine one indicator that must correlate positively with the construct and thus dictates the orientation of the construct.

Apart from theoretical model identification, empirical identification must be taken into account (Kenny, 1979). Although a model is in principle identified by its structure, i.e. justidentified or over-identified, model parameters can be undetermined and unstable due to the indicator sample covariance matrix. As a consequence, the empirical distribution of estimated parameters can be bimodal (Rönkkö and Evermann, 2013). In such a situation, it is recommended to employ predefined weights or weights obtained from other techniques such as principal component analysis. 


\section{JHTT \\ 9,3}

\section{Model assessment}

After the identification of the model is ensured and the parameter estimates are obtained, the estimated model must be evaluated. While the use of PLS-PM is prevalent in many fields, e.g. information systems research (Marcoulides and Saunders, 2006) or marketing research (Hair et al., 2012), in TTH, its use remains scarce (Ali et al., 2018). Therefore, in the following section, we provide guidelines on the assessment of the overall model, the structural model, and the incorporated constructs.

\subsection{Assessing the overall model}

An acceptable overall model fit is required before interpreting the parameter estimates because it indicates whether the underlying theory is reflected in the data. To obtain empirical evidence on whether the estimated model fits the collected data, the estimated model is compared to the saturated model, i.e. a model that perfectly fits the data. For this purpose, several distance measures have been proposed, such as the geodesic distance $\left(d_{G}\right)$, the Euclidean distance $\left(d_{L}\right)$ and the standardized root mean squared residual (SRMR). The reference distribution of these measures can be obtained by bootstrap, which allows for statistical inferences on the fit of the estimated model (Beran and Srivastava, 1985). Depending on the assumed significance level, the value of the discrepancy measure based on the original data set is compared to the 95 or 99 per cent quantiles of the reference distribution for decision-making. The null hypothesis assuming that the population covariance matrix of the indicators equals the population covariance matrix implied by the model is rejected when the value of the measure is larger than the quantile of the reference distribution (Henseler et al., 2016).

However, in many empirical studies, there is often a statistically significant discrepancy between the empirical and the model-implied covariance matrix. Therefore, more and more scholars rely on measures of model fit such as the SRMR instead of on statistical testing and compare the value of the measure to threshold values recommended in the literature (Barrett, 2007). It is emphasized that this practice should be performed cautiously because measures of model fit are based on heuristic rules. Generally, researchers facing a rejected model are better advised to examine the sources of the model's lack of fit instead of moving to measures of fit, e.g. by considering the residual matrix.

\subsection{Assessing the common factor and composite model}

Once the overall model shows an acceptable fit, the common factor and the composite models incorporated into the model must be assessed.

5.2.1 Common factor model. The assessment of the common factor model refers to the investigation of construct validity. However, the question of validity can be answered in various non-exclusive ways. Following Ali et al. (2018), we consider:

- the indicator reliability;

- internal consistency;

- convergent validity; and

- discriminant validity to assess the common factor model.

While indicator reliability is typically assessed by examining the standardized factor loadings, internal consistency is assessed through the correlations among the indicators belonging to one construct, reflecting the reliability of the reflective measurement model. To evaluate internal consistency for a block of indicators belonging to one latent variable, the use of the reliability measures $\rho_{A}$ (Dijkstra and Henseler, 2015a) and Raykov's r (Raykov, 1997) is recommended. 
Furthermore, measures of composite reliability such as Dillon-Goldstein's $\rho$ - also known as Jöreskog $\rho_{c}$ (Chin, 1998) - or Cronbach's $\alpha$ are also applied in this context. However, Cronbach's $\alpha$ usually underestimates the true reliability and should therefore be considered only as a lower boundary (Sijtsma, 2009).

Moreover, convergent validity refers to the extent to which the effect indicators belonging to one construct actually measure the same construct. Typically, the average variance extracted (AVE) is used as a measure of convergent validity (Fornell and Cha, 1994). AVE indicates how much of the indicators' variance can be explained by the underlying factor. Therefore, an AVE larger than 0.5 has been established to show convergent validity, as the underlying factor explains more than the half of the variance and, consequently, all other factors can only explain less (Fornell and Larcker, 1981).

In contrast to convergent validity, discriminant validity refers to the extent to which a given latent variable differs from the other latent variables in the model. Thus, empirical evidence for discriminant validity is provided when indicators of distinct latent variables are not highly correlated. Discriminant validity is preferably assessed by the FornellLarcker criterion, i.e. a factor's AVE should be higher than its squared correlations with all other factors in the model, or by the recently introduced heterotrait-monotrait ratio of common factor correlations (HTMT) (Fornell and Larcker, 1981; Henseler et al., 2015). For the HTMT, all values should be significantly lower than 1 . As a recommended threshold, a value of 0.85 has been established to provide sufficient evidence of the discriminant validity of a pair of constructs (Voorhees et al., 2016). To avoid the use of heuristic rules for the HTMT, bootstrapping can be applied to construct confidence intervals (Henseler et al., 2015). To obtain further evidence of discriminant validity, cross-loadings are usually considered. In doing so, all cross-loadings of an indicator, i.e. the correlations between the indicator and the other constructs, should be smaller than the corresponding factor loading.

5.2.2 Composite model. As the composite model follows a different notion than the common factor, most of the assessment criteria for common factor models are not applicable to the assessment of the composite model. Following Henseler (2017), the composite model should be assessed by the three characteristics:

(1) nomological validity;

(2) reliability; and

(3) composition.

As the composite model is not identified on its own, the composite must be embedded in a nomological net, i.e. connected to at least two antecedents and/or consequences, to assess its nomological validity[2]. To obtain empirical evidence of nomological validity, the test of overall model fit from Section 5.1 can be applied to the model with a saturated structural model, i.e. the structural model of the specified model is ignored during the evaluation of the model fit. When the model containing the composite does not show a significantly worse fit than the model without the composite, the composite can be said to have nomological validity. Thus, it can be inferred that the composite - rather than the individual indicators acts within a nomological net.

Besides nomological validity, composite reliability must be evaluated because it may need to be adjusted. Typically, the indicators forming the composite are assumed to be free from measurement error; therefore, the composite reliability is equal to 1 . However, if the researcher doubts this assumption, indicator reliabilities can be taken into account during the estimation. In contrast to the common factor model with multiple indicators, the share of 
JHTT

9,3

258

random measurement error in the indicators must be determined externally, e.g. by previous studies.

Finally, the estimated weights should be examined with respect to their statistical significance, size and sign. In this context, considering collinearity among the indicators that form a composite is particularly important when mode $B$ is applied, as it can lead to unexpected signs and huge bootstrap confidence intervals.

\subsection{Assessing the structural model}

Once the common factor and the composite models are deemed to be of sufficient quality, in the next step, the researcher should focus on the structural model. Assuming that the structural model is estimated by OLS, the coefficient of determination $R^{2}$ for the endogenous constructs is usually considered[3]. The $R^{2}$ value indicates how much of the variance in an endogenous variable is explained by its antecedent constructs. As the $R^{2}$ practically always increases by adding a construct to the explanation of an endogenous construct, consideration of the adjusted $R^{2}$ is more reasonable when comparing different models (Hair et al., 2014).

Subsequently, to draw conclusions about the underlying population, the path coefficients should be evaluated for their significances, i.e. statistical significance and practical significance. In PLS-PM, the statistical significance of the path coefficient estimates can be assessed by bootstrap confidence intervals. In doing so, whether the bootstrap confidence interval covers the zero is investigated. If this is not the case, it is assumed that the path coefficient in the underlying population is different from zero. Various ways to determine bootstrap confidence intervals exist; among them, the percentile bootstrap confidence intervals are most recommendable (Aguirre-Urreta and Rönkkö, 2018). In this context, multicollinearity should be investigated (for instance, by means of the variance inflation factor), since high collinearity among the explanatory constructs can mask potential significant effects. To evaluate whether a statistically significant effect also has practical relevance, it makes sense to evaluate its effect size $f^{2}$. Following Cohen (1988), values above 0.35, 0.15 , and 0.02 are regarded as strong, moderate and weak, respectively. Moreover, the assessment of the structural model should involve the interpretation of the coefficient estimates. Depending on the sign, the direct effects equaling the estimated coefficients are interpreted as the change in standard deviations of the dependent variable if the independent variable increases by one standard deviation keeping all other variables constant, i.e. ceteris paribus.

Not only the direct effects but also the indirect effects and the total effects are important. While the former are particularly relevant in mediation analysis (Zhao et al., 2010), the latter are useful for business success factor studies (Albers, 2010).

\section{Empirical example}

In the following, we demonstrate how PLS-PM can be used as a confirmatory approach to estimate structural models containing latent variables and artifacts by adopting the empirical study of Rezaei et al. (2016). These authors consider a sample of 405 individuals to examine the relationship between website personality (WSP), utilitarian web browsing (UWB), hedonic web browsing (HWB), and online impulse buying of tourism products (OIB). Since the original study provides only the construct correlation matrix, a simulated dataset is used. For this purpose, we draw a sample from the multivariate normal distribution of exactly the same size and with an identical mean and covariance structure as the original sample. To estimate the two models from Figure 2 using PLS-PM, we use ADANCO 


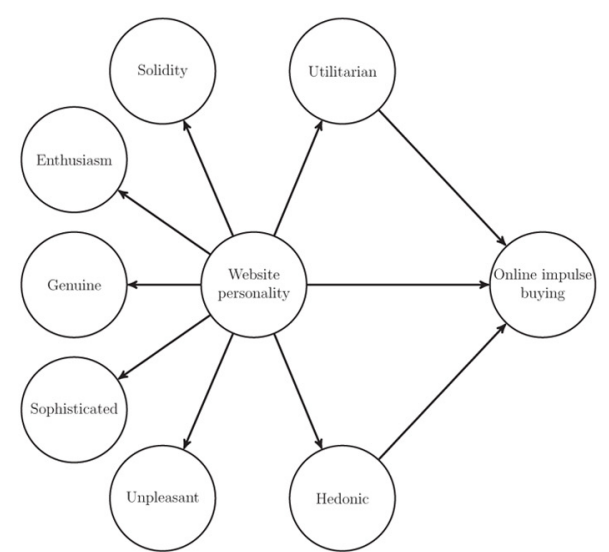

(a)

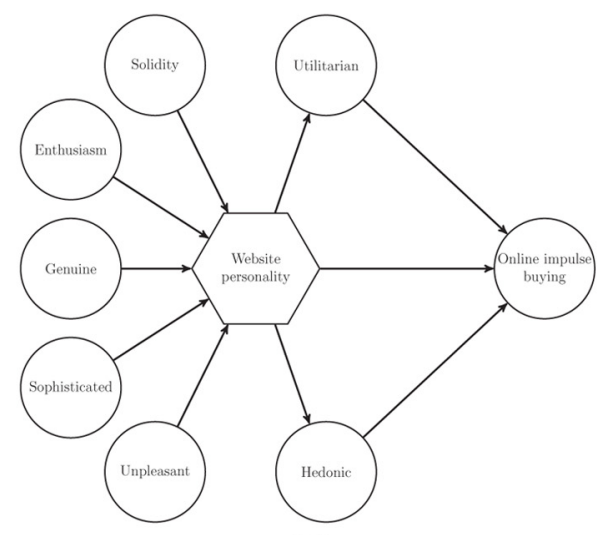

(b)

Notes: (a) Website personality modeled as a common factor; (b) website personality modeled as a composite

Figure 2. Estimated models

(Henseler and Dijkstra, 2017). In doing so, the factorial scheme is applied for inner weighting and $10^{-6}$ is set as stopping criterion in the PLS algorithm.

As a starting point, we re-estimate the original model displayed in Figure 2a assuming that the construct website personality is a latent variable that is measured by the following five constructs: solidity; enthusiasm; genuineness; sophistication; and unpleasantness [4]. As the empirical study serves only as a showcase, the original article should be consulted for more information on the theoretical model and the constructs used. Compared to the original study, we obtain different path coefficient estimates because PLSc is used to obtain consistent parameter estimates for models containing common factors. Table I contrasts the original results from Rezaei et al. (2016) with those obtained by PLSc. Additionally, the 95 per cent percentile bootstrap confidence intervals (CIs) for the path coefficient estimates are reported.

To obtain empirical evidence for the specified model, its overall model fit must be assessed. In doing so, it is helpful to also assess a saturated model, i.e. a model with a saturated structural model (Gefen et al., 2011). The model with a saturated structural model ignores potential misspecifications in the structural model and is therefore helpful to assess the measurement model. Considering Table I, the results for the tests of overall model fit

\begin{tabular}{|c|c|c|c|c|c|}
\hline & \multirow{2}{*}{$\begin{array}{l}\text { Original model } \\
\text { Estimate }\end{array}$} & \multicolumn{2}{|c|}{ WSP modeled as common factor } & \multicolumn{2}{|c|}{ WSP modeled as composite } \\
\hline & & Estimate & $\mathrm{CI}$ & Estimate & $\mathrm{CI}$ \\
\hline $\mathrm{WSP} \rightarrow \mathrm{UWB}$ & 0.818 & $0.933^{* * * *}$ & {$[0.913 ; 0.951]$} & $0.890 * * *$ & {$[0.870 ; 0.909]$} \\
\hline $\mathrm{WSP} \rightarrow \mathrm{HWB}$ & 0.789 & $0.867 * * *$ & {$[0.833 ; 0.898]$} & $0.832 * * *$ & {$[0.800 ; 0.861]$} \\
\hline $\mathrm{WSP} \rightarrow \mathrm{OIB}$ & 0.402 & $1.032^{* * * *}$ & {$[0.646 ; 1.539]$} & $0.606^{* * * *}$ & {$[0.467 ; 0.761]$} \\
\hline $\mathrm{UWB} \rightarrow \mathrm{OIB}$ & 0.168 & $-0.302^{*}$ & {$[-0.651 ;-0.032]$} & 0.002 & {$[-0.129 ; 0.131]$} \\
\hline $\mathrm{HWB} \rightarrow \mathrm{OIB}$ & 0.218 & 0.008 & {$[-0.245 ; 0.184]$} & $0.161^{* *}$ & {$[0.041 ; 0.263]$} \\
\hline
\end{tabular}

Notes: ***Significant on a $1 \%$ level; **significant on a $5 \%$ level; * significant on a $10 \%$ level

Table I.

Path coefficient estimates and confidence intervals 


\section{JHTT 9,3}

give no empirical evidence for the model containing website personality modeled as a common factor. The values for $d_{L}, d_{G}$ and SRMR are all above the 99 per cent quantile (HI99) of their corresponding empirical distribution for the estimated and the saturated model. Therefore, all tests reject the null hypothesis at a 1 per cent significance level that the indicator population covariance matrix equals the indicator population covariance matrix implied by the model. Hence, factorial validity is not provided, and it is very unlikely that the empirical data stem from a world that functions as theorized by the assumed model.

As the test for overall model fit was introduced only recently (Dijkstra and Henseler, 2015a), the original study could not provide any test results. However, for future studies, we highly recommend reporting the overall model fit of the estimated model, as a fitting model is required before the model can be further assessed; see Section 5 .

We might also take the role of a researcher who assumes that website personality is an artifact instead of a latent variable; see the model depicted in Figure 2b. Hence, website personality is modeled as a composite. A potential research question might be whether it makes sense to create the artifact website personality out of solidity, enthusiasm, genuineness, sophistication, and unpleasantness. While Table II contains the results of the test for overall model fit, Table I reports the path coefficient estimates. Again, all tests of overall model fit are rejected for the estimated and saturated model, and therefore, empirical evidence for the nomological validity of the composite is unfounded.

\section{Discussion}

\subsection{Conclusions}

TTH research specially challenges statistical tools as combining design and behavioral research plays a crucial role in this discipline. Current studies mostly consider only latent variables; hence, interesting research questions concerning the design character of TTH can only be limited answered. Therefore, the study at hand shows how PLS-PM can be applied in a confirmatory way to SEM, addressing the needs of both strands of science by modeling behavioral constructs - so-called latent variables - with common factors and design constructs - so-called artifacts - with composites. This approach is particularly useful because it enables scholars to ask new research questions of the type "Is it useful to create the artifact xyz?", further contributing to the understanding of TTH.

\subsection{Theoretical implications}

Besides emphasizing the importance of the overall model fit in PLS-PM, the study at hand provides a modern view of PLS-PM for confirmatory purposes and state-of-the-art reporting standards for common factor and composite models. Apart from properly reporting the PLS-PM results, researchers must justify their use of PLS-PM since primary journals have already begun to desk-reject manuscripts using PLS-PM due to flawed arguments

Table II.

Results of the test for overall model fit

\begin{tabular}{|c|c|c|c|c|c|c|c|c|c|}
\hline \multirow[b]{3}{*}{ Original model } & & \multicolumn{4}{|c|}{ WSP modeled as common factor } & \multicolumn{4}{|c|}{ WSP modeled as composite } \\
\hline & & \multicolumn{2}{|c|}{ Estimated } & \multicolumn{2}{|c|}{ Saturated } & \multicolumn{2}{|c|}{ Estimated } & \multicolumn{2}{|c|}{ Saturated } \\
\hline & & Stat. & HI99 & Stat. & HI99 & Stat. & HI99 & Stat. & HI99 \\
\hline $\mathrm{dL}$ & NA & $0.0791 * * *$ & 0.0146 & $0.0783 * * *$ & 0.0142 & $0.0385^{* * *}$ & 0.0089 & $0.0367 * * *$ & 0.0083 \\
\hline SRMR & NA & $0.0469 * * * *$ & 0.0202 & $0.0466 * * *$ & 0.0199 & $0.0327 * * *$ & 0.0157 & $0.0319 * * *$ & 0.0152 \\
\hline $\mathrm{dG}$ & NA & $0.1045^{* * * *}$ & 0.0181 & $0.1027 * * *$ & 0.0162 & $0.0665^{* * * *}$ & 0.0111 & $0.0603^{* * * *}$ & 0.0104 \\
\hline
\end{tabular}

Notes: ***Significant on a 1\% level. To obtain the reference distribution, 999 bootstrap runs are conducted 
(Guide and Ketokivi, 2015). Although the test for overall model fit was introduced only recently to PLS-PM, its use is highly recommended for confirmatory analysis in general. Without considering its results, researchers cannot statistically conclude that the set-up theory matches with the collected data. Moreover, outdated justifications, such as PLS-PM is advantageous in situations with small sample sizes, non-normal data or causal-formative measurement models, should be avoided (Rigdon, 2016).

\subsection{Practical implications}

To benefit the recently introduced methodological and conceptual achievements in PLS-PM, TTH scholars need guidelines for their empirical studies that take into account these new developments and insights. The study at hand provides such guidelines and enables practitioners in the TTH field to develop and apply new technologies according customers' demands. In doing so, researchers benefit from the use of PLS-PM for confirmatory purposes, as it can estimate structural models containing both behavioral and design constructs.

\subsection{Limitations and future research}

In our study, we distinguish between two kinds of constructs - the latent variable and the artifact - to justify the use of composites and PLS-PM. However, taking a purely realist perspective can also be used to justify the use of PLS-PM, which assumes that both a common factor and a composite can serve as proxies for latent variables (Rigdon et al., 2017; Sarstedt et al., 2016b).

Moreover, the study at hand focuses primarily on PLS-PM for confirmatory purposes; however, the predictive capabilities of PLS-PM should not be disregarded (Becker et al., 2013; Sarstedt et al., 2014, 2017; Wold, 1985). In predictive modeling, the model parameter estimates based on one sample are applied to generate predictions for individual cases outside of that sample (out-of-sample prediction). Hence, the assessment of predictive models requires different criteria such as the predictive power of the model (Shmueli, 2010; Shmueli et al., 2016). In the context of TTH, predictive modeling might be an additional field of application of PLS-PM. For inspiration on the use of PLS-PM as a tool for predictive modeling, TTH scholars should refer to the special issue of the Journal of Business Research (Cepeda Carrión et al., 2016).

\section{Notes}

1. We ignore trivial regularity assumptions such as weight vectors containing zeros only or nonsemi-positive-definite indicator covariance matrices.

2. A composite with at least two antecedents/consequences provides an over-identified model. In the case of one antecedent/consequence, the model is just-identified and its overall model fit should not be assessed.

3. The $R^{2}$ can be used not only in confirmatory research but also in predictive research as a metric that provides insights into a model's out-of-sample predictive power. For an empirical example applying PLS-PM, see the study by Miltgen et al. (2016).

4. As neither the indicator correlation matrix nor the original data set are publicly available, we could not apply the repeated-indicators approach (Wold, 1982) originally used or the three-stage approach (Van Riel et al., 2017). Therefore, we take the first-order constructs as indicators for the second-order construct and assume the consistency of the reported construct correlation matrix. 


\section{JHTT \\ 9,3}

\section{References}

Aguirre-Urreta, M.I. and Rönkkö, M. (2018), “Statistical inference with PLSc using bootstrap confidence intervals”, MIS Quarterly, Vol. 42 No. 3, pp. 1001-1020.

Albers, S. (2010), "PLS and success factor studies in marketing", in Handbook of Partial Least Squares, Springer, Berlin, pp. 409-425.

Ali, F. (2016), "Hotel website quality, perceived flow, customer satisfaction and purchase intention", Journal of Hospitality and Tourism Technology, Vol. 7 No. 2, pp. 213-228.

Ali, F., Rasoolimanesh, S.M., Sarstedt, M., Ringle, C.M. and Ryu, K. (2018), "An assessment of the use of partial least squares structural equation modeling (PLS-SEM) in hospitality research", International Journal of Contemporary Hospitality Management, Vol. 30 No. 1, pp. 514-538.

Antonakis, J., Bendahan, S., Jacquart, P. and Lalive, R. (2010), "On making causal claims: a review and recommendations", The Leadership Quarterly, Vol. 21 No. 6, pp. 1086-1120.

Balouchi, M., Aziz, Y.A., Hasangholipour, T., Khanlari, A., Rahman, A.A. and Raja-Yusof, R.N. (2017), "Explaining and predicting online tourists' behavioural intention in accepting consumer generated contents", Journal of Hospitality and Tourism Technology, Vol. 8 No. 2, pp. 168-189.

Barrett, P. (2007), "Structural equation modelling: adjudging model fit", Personality and Individual Differences, Vol. 42 No. 5, pp. 815-824.

Becker, J.-M., Rai, A. and Rigdon, E. (2013), "Predictive validity and formative measurement in structural equation modeling: embracing practical relevance", in 34th International Conference on Information Systems, Milan, pp. 1-19.

Benitez, J., Henseler, J. and Roldán, J. (2016), "How to address endogeneity in partial least squares path modeling", in 22nd Americas Conference on Information Systems, San Diego, pp. 1-10.

Beran, R. and Srivastava, M.S. (1985), "Bootstrap tests and confidence regions for functions of a covariance matrix", The Annals of Statistics, Vol. 13 No. 1, pp. 95-115.

Bilgihan, A., Okumus, F., Nusair, K.K. and Kwun, D.J.-W. (2011), "Information technology applications and competitive advantage in hotel companies", Journal of Hospitality and Tourism Technology, Vol. 2 No. 2, pp. 139-153.

Blackshaw, P. and Nazzaro, M. (2006), Consumer-Generated Media (CGM) 101: Word-of-Mouth in the Age of the Web-Fortified Consumer, Nielsen BuzzMetrics, New York, NY.

Bollen, K.A. (1989), Structural Equations with Latent Variables, John Wiley and Sons Inc, New York, NY.

Bollen, K.A. and Bauldry, S. (2011), "Three cs in measurement models: causal indicators, composite indicators, and covariates", Psychological Methods, Vol. 16 No. 3, pp. 265-284.

Borsboom, D., Mellenbergh, G.J. and van Heerden, J. (2003), “The theoretical status of latent variables", Psychological Review, Vol. 110 No. 2, pp. 203-219.

Cepeda Carrión, G., Henseler, J., Ringle, C.M. and Roldán, J.L. (2016), "Prediction-oriented modeling in business research by means of PLS path modeling: introduction to a JBR special section", Journal of Business Research, Vol. 69 No. 10, pp. 4545-4551.

Chin, W.W. (1998), "The partial least squares approach for structural equation modeling", in Marcoulides, G.A. (Ed.), Modern Methods for Business Research, Psychology Press, Hove, pp. 295-336.

Clemenz, C.E., Weaver, P.A. and Gore, F. (2000), "ClubCorp goes to school: developing a computer-based training program”, The Cornell Hotel and Restaurant Administration Quarterly, Vol. 41 No. 6, pp. 34-39.

Cohen, J. (1988), Statistical Power Analysis for the Behavioral Sciences, Lawrence Erlbaum Associates, Hillsdale.

Collins, G., Cobanoglu, C. and Bilgihan, A. (2013), Hospitality Information Technology: Learning How to Use It, 7th ed., Kendall Hunt Publishing, Dubuque. 
Deng, W., Yeh, M. and Sung, M. (2013), "A customer satisfaction index model for international tourist hotels: integrating consumption emotions into the american customer satisfaction index", International Journal of Hospitality Management, Vol. 35, pp. 133-140.

Di Pietro, L., Di Virgilio, F. and Pantano, E. (2012), "Social network for the choice of tourist destination: attitude and behavioural intention", Journal of Hospitality and Tourism Technology, Vol. 3 No. 1, pp. 60-76.

Diamantopoulos, A., Sarstedt, M., Fuchs, C., Wilczynski, P. and Kaiser, S. (2012), "Guidelines for choosing between multi-item and single-item scales for construct measurement: a predictive validity perspective”, Journal of the Academy of Marketing Science, Vol. 40 No. 3, pp. 434-449.

Dijkstra, T.K. (2013), "On the extraction of weights from pairwise comparison matrices", Central European Journal of Operations Research, Vol. 21 No. 1, pp. 103-123.

Dijkstra, T.K. (2017), "A perfect match between a model and a mode”, in Latan, H. and Noonan, R. (Eds), Partial Least Squares Path Modeling: Basic Concepts, Methodological Issues and Applications, Springer, pp. 55-80.

Dijkstra, T.K. and Henseler, J. (2015a), "Consistent and asymptotically normal PLS estimators for linear structural equations", Computational Statistics and Data Analysis, Vol. 81, pp. 10-23.

Dijkstra, T.K. and Henseler, J. (2015b), "Consistent partial least squares path modeling”, MIS Quarterly, Vol. 39 No. 2, pp. 297-316.

Dijkstra, T.K. and Schermelleh-Engel, K. (2014), "Consistent partial least squares for nonlinear structural equation models", Psychometrika, Vol. 79 No. 4, pp. 585-604.

Fornell, C. and Cha, J. (1994), "Partial least squares", in Bagozzi, R. (Ed.), Advanced Methods of Marketing Research, Blackwell, Oxford, pp. 52-78.

Fornell, C. and Larcker, D.F. (1981), "Evaluating structural equation models with unobservable variables and measurement error", Journal of Marketing Research, Vol. 18 No. 1, pp. 39-50.

Gefen, D., Rigdon, E. and Straub, D. (2011), "An update and extension to SEM guidelines for administrative and social science research", MIS Quarterly, Vol. 35 No. 2, pp. iii-xiv.

Gretzel, U., Kang, M. and Lee, W. (2008), "Differences in consumer-generated media adoption and use: a cross-national perspective", Journal of Hospitality and Leisure Marketing, Vol. 17 Nos 1/2, pp. 99-120.

Guide, V.D.R. and Ketokivi, M. (2015), "Notes from the editors: redefining some methodological criteria for the journal”, Journal of Operations Management, Vol. 37, pp. v-viii.

Hair, J.F., Hult, G.T.M., Ringle, C.M., Sarstedt, M. and Thiele, K.O. (2017a), "Mirror, mirror on the wall: a comparative evaluation of composite-based structural equation modeling methods", Journal of the Academy of Marketing Science, pp. 1-17.

Hair, J.F., Sarstedt, M., Hopkins, L. and Kuppelwieser, V.G. (2014), "Partial least squares structural equation modeling (PLS-SEM): an emerging tool in business research", European Business Review, Vol. 26 No. 2, pp. 106-121.

Hair, J.F., Ringle, C.M. and Sarstedt, M. (2011), "PLS-SEM: Indeed a silver bullet”, The Journal of Marketing Theory and Practice, Vol. 19 No. 2, pp. 139-152.

Hair, J.F., Sarstedt, M., Ringle, C.M. and Mena, J.A. (2012), "An assessment of the use of partial least squares structural equation modeling in marketing research", Journal of the Academy of Marketing Science, Vol. 40 No. 3, pp. 414-433.

Hair, J.F., Hollingsworth, C., Randolph, A. and Chong, A. (2017b), "An updated and expanded assessment of PLS-SEM in information systems research", Industrial Management and Data Systems, Vol. 117 No. 3, pp. 442-458.

Hayduk, L.A. and Littvay, L. (2012), "Should researchers use single indicators, best indicators, or multiple indicators in structural equation models?", BMC Medical Research Methodology, Vol. 12 No. 1, pp. 159. 
Henseler, J. (2017), "Bridging design and behavioral research with variance-based structural equation modeling", Journal of Advertising, Vol. 46 No. 1, pp. 178-192.

Henseler, J. and Dijkstra, T. (2017), “Adanco 2.0.1”, Composite Modeling, Kleve, Germany.

Henseler, J., Dijkstra, T.K., Sarstedt, M., Ringle, C.M., Diamantopoulos, A., Straub, D.W., Ketchen, D.J., Hair, J.F., Hult, G.T.M. and Calantone, R.J. (2014a), "Common beliefs and reality about PLS: comments on Rönkkö and Evermann (2013)", Organizational Research Methods, Vol. 17 No. 2, pp. 182-209.

Henseler, J., Hubona, G. and Ray, P.A. (2016), "Using PLS path modeling in new technology research: updated guidelines”, Industrial Management and Data Systems, Vol. 116 No. 1, pp. 2-20.

Henseler, J., Ringle, C.M. and Sarstedt, M. (2015), "A new criterion for assessing discriminant validity in variance-based structural equation modeling”, Journal of the Academy of Marketing Science, Vol. 43 No. 1, pp. 1-21.

Holt, D.B. (1995), "How consumers consume: a typology of consumption practices", Journal of Consumer Research, Vol. 22 No. 1, pp. 1-16.

Hsiao, T.-Y., Chuang, C.-M. and Huang, L. (2018), "The contents, determinants, and strategic procedure for implementing suitable green activities in star hotels", International Journal of Hospitality Management, Vol. 69, pp. 1-13.

Huang, Y., Huang, F., Hsu, M.K. and Chang, F. (2009), "Determinants and outcomes of relationship quality: an empirical investigation on the Chinese travel industry", Asia Pacific Journal of Tourism Research, Vol. 14 No. 1, pp. 59-75.

Hult, G.T.M., Hair, J.F. Jr, Proksch, D., Sarstedt, M., Pinkwart, A. and Ringle, C.M. (2018), “Addressing endogeneity in international marketing applications of partial least squares structural equation modeling”, Journal of International Marketing, Vol. 26 No. 3, pp. 1-21.

Hwang, H. and Takane, Y. (2004), "Generalized structured component analysis", Psychometrika, Vol. 69 No. 1, pp. 81-99.

Ip, C., Leung, R. and Law, R. (2011), "Progress and development of information and communication technologies in hospitality", International Journal of Contemporary Hospitality Management, Vol. 23 No. 4, pp. 533-551.

Jeon, S.M., Magnini, V.P., Kim, I. and Hyun, S.S. (2013), "Causal relationships between table game players' perceptions of service quality, perceived winning, and game spending”, International Journal of Contemporary Hospitality Management, Vol. 25 No. 6, pp. 922-944.

Jöreskog, K. (1969), “A general approach to confirmatory maximum likelihood factor analysis", Psychometrika, Vol. 34 No. 2, pp. 183-202.

Kamboj, S. and Rahman, Z. (2017), "Measuring customer social participation in online travel communities", Journal of Hospitality and Tourism Technology, Vol. 8 No. 3, pp. 432-464.

Kenny, D.A. (1979), Correlation and Causality, John Wiley and Sons Inc, Hoboken.

Kettenring, J.R. (1971), “Canonical analysis of several sets of variables”, Biometrika, Vol. 58 No. 3, pp. $433-451$.

King, C., Murillo, E. and Lee, H. (2017), "The effects of generational work values on employee brand attitude and behavior: a multi-group analysis", International Journal of Hospitality Management, Vol. 66, pp. 92-105.

Lohmöller, J.-B. (2013), Latent Variable Path Modeling with Partial Least Squares, Springer Science and Business Media.

Marcoulides, G.A. and Saunders, C. (2006), "Editor's comments: PLS: a silver bullet?”, MIS Quarterly, Vol. 30 No. 2, pp. iii-iix.

Miltgen, C.L., Henseler, J., Gelhard, C. and Popovič, A. (2016), "Introducing new products that affect consumer privacy: a mediation model", Journal of Business Research, Vol. 69 No. 10, pp. 4659-4666. 
Moliner, M.A., Sánchez, J., Rodríguez, R.M. and Callarisa, L. (2007), "Relationship quality with a travel agency: the influence of the postpurchase perceived value of a tourism package", Tourism and Hospitality Research, Vol. 7 Nos 3/4, pp. 194-211.

O'Connor, P. (2008), "User-generated content and travel: a case study on tripadvisor.com", in O'Connor, P., Höpken, W. and Gretzel, U. (Eds), Information and Communication Technologies in Tourism 2008, Springer, Vienna, pp. 47-58.

Pan, B. and Crotts, J. (2012), "Theoretical models of social media, marketing implications, and future research directions", in Sigala, M., Christou, E. and Gretzel, U. (Eds), Social Media in Travel, Tourism and Hospitality: Theory, Practice and Cases, Ashgate, Surrey, pp. 73-85.

Pan, B., MacLaurin, T. and Crotts, J.C. (2007), "Travel blogs and the implications for destination marketing", Journal of Travel Research, Vol. 46 No. 1, pp. 35-45.

Rademaker, M., Schuberth, F. and Dijkstra, T.K. (forthcoming), "Measurement error correlation within blocks of indicators in consistent partial least squares: issues and remedies", Internet Research.

Raykov, T. (1997), "Estimation of composite reliability for congeneric measures", Applied Psychological Measurement, Vol. 21 No. 2, pp. 173-184.

Rezaei, S., Ali, F., Amin, M. and Jayashree, S. (2016), "Online impulse buying of tourism products: the role of web site personality, utilitarian and hedonic web browsing", Journal of Hospitality and Tourism Technology, Vol. 7 No. 1, pp. 60-83.

Rigdon, E.E. (2016), "Choosing PLS path modeling as analytical method in European management research: a realist perspective”, European Management Journal, Vol. 34 No. 6, pp. 598-605.

Rigdon, E.E., Sarstedt, M. and Ringle, C.M. (2017), "On comparing results from CB-SEM and PLS-SEM: Five perspectives and five recommendations", Marketing Zfp, Vol. 39 No. 3, pp. 4-16.

Ringle, C.M., Sarstedt, M., Mitchell, R. and Gudergan, S.P. (2018), "Partial least squares structural equation modeling in HRM research", The International Journal of Human Resource Management, pp. 1-27.

Rönkkö, M. and Evermann, J. (2013), "A critical examination of common beliefs about partial least squares path modeling”, Organizational Research Methods, Vol. 16 No. 3, pp. 425-448.

Rönkkö, M., Evermann, J. and Aguirre-Urreta, M. (2016), "Estimating formative measurement models in IS research - analysis of the past and recommendations for the future", working paper.

Rönkkö, M., McIntosh, C.N., Antonakis, J. and Edwards, J.R. (2016), "Partial least squares path modeling: time for some serious second thoughts", Journal of Operations Management, Vols 47/48, pp. 9-27.

Sarstedt, M., Diamantopoulos, A. and Salzberger, T. (2016a), "Should we use single items? Better not", Journal of Business Research, Vol. 69 No. 8, pp. 3199-3203.

Sarstedt, M., Hair, J.F., Ringle, C.M., Thiele, K.O. and Gudergan, S.P. (2016b), "Estimation issue with PLS and CBSEM: where the bias lies!", Journal of Business Research, Vol. 69 No. 10, pp. 3998-4010.

Sarstedt, M., Ringle, C.M. and Hair, J.F. (2017), "Partial least squares structural equation modeling”, in Homburg, C., Klarmann, M. and Vomberg, A. (Eds), Handbook of Market Research, Springer, Berlin, pp. 1-40.

Sarstedt, M., Ringle, C.M., Henseler, J. and Hair, J.F. (2014), "On the emancipation of PLS-SEM: a commentary on Rigdon (2012)", Long Range Planning, Vol. 47 No. 3, pp. 154-160.

Schuberth, F. and Cantaluppi, G. (2017), "Ordinal consistent partial least squares", in Latan, H. and Noonan, R. (Eds), Recent Developments in PLS-SEM: Basic Concepts, Methodological Issues and Applications, Springer, pp. 109-150.

Schuberth, F., Henseler, J. and Dijkstra, T.K. (2018), "Partial least squares path modeling using ordinal categorical indicators", Quality and Quantity, Vol. 52 No. 1, pp. 9-35.

Shmueli, G. (2010), “To explain or to predict?”, Statistical Science, Vol. 25 No. 3, pp. 289-310. 
JHTT

9,3

Shmueli, G., Ray, S., Estrada, J.M.V. and Chatla, S.B. (2016), "The elephant in the room: predictive performance of PLS models", Journal of Business Research, Vol. 69 No. 10, pp. 4552-4564.

Sijtsma, K. (2009), "On the use, the misuse, and the very limited usefulness of Cronbach's alpha", Psychometrika, Vol. 74 No. 1, pp. 107-120.

Simon, H. (1969), The Sciences of the Artificial, MA, Cambridge.

Sox, C.B., Campbell, J.M., Kline, S.F., Strick, S.K. and Crews, T.B. (2016), “Technology use within meetings: a generational perspective", Journal of Hospitality and Tourism Technology, Vol. 7 No. 2, pp. 158-181.

Spearman, C. (1904), "General intelligence,' objectively determined and measured", The American Journal of Psychology, Vol. 15 No. 2, pp. 201-292.

Steiger, J.H. (1979), "Factor indeterminacy in the 1930's and the 1970's some interesting parallels", Psychometrika, Vol. 44 No. 2, pp. 157-167.

Tenenhaus, M., Vinzi, V.E., Chatelin, Y.-M. and Lauro, C. (2005), "PLS path modeling”, Computational Statistics and Data Analysis, Vol. 48 No. 1, pp. 159-205.

Van Riel, A.C.R., Henseler, J., Kemény, I. and Sasovova, Z. (2017), "Estimating hierarchical constructs using partial least squares: the case of second order composites of factors", Industrial Management and Data Systems, Vol. 117 No. 3, pp. 459-477.

Voorhees, C.M., Brady, M.K., Calantone, R. and Ramirez, E. (2016), "Discriminant validity testing in marketing: an analysis, causes for concern, and proposed remedies", Journal of the Academy of Marketing Science, Vol. 44 No. 1, pp. 119-134.

Wang, L., Law, R., Guillet, B.D., Hung, K. and Fong, D.K.C. (2015), "Impact of hotel website quality on online booking intentions: eTrust as a mediator", International Journal of Hospitality Management, Vol. 47, pp. 108-115.

Wanous, J.P. and Reichers, A.E. (1996), "Estimating the reliability of a single-item measure", Psychological Reports, Vol. 78 No. 2, pp. 631-634.

Wold, H. (1975), "Path models with latent variables: the NIPALS approach", in Blalock, H., Aganbegian, A., Borodkin, F., Boudon, R. and Capecchi, V. (Eds), Quantitative Sociology, Academic Press, New York, NY, International Perspectives on Mathematical and Statistical Modeling, pp. 307-357.

Wold, H. (1985), "Systems analysis by partial least squares", in Nijkamp P., Leitner, H. and Wrigley, N. (Eds), Measuring the Unmeasurable, Martinus Nijhoff Publishers, pp. 221-251.

Wold, H.O.A. (1982), "Soft modeling the basic design and some extensions", in Jöreskog, K.G. and Wold, H. (Eds), Systems under Indirect Observation: Causality, Structure, Prediction Part II, NorthHolland, Amsterdam, pp. 1-54.

Zhao, X., Lynch, J.G. and Chen, Q. (2010), "Reconsidering baron and kenny: Myths and truths about mediation analysis", Journal of Consumer Research, Vol. 37 No. 2, pp. 197-206.

\section{Corresponding author}

Tobias Müller can be contacted at: t.muller@utwente.nl

For instructions on how to order reprints of this article, please visit our website:

www.emeraldgrouppublishing.com/licensing/reprints.htm

Or contact us for further details: permissions@emeraldinsight.com 